\title{
LITERATURA FANTÁSTICA CHILENA ACTUAL — UNA LECTURA POLÍTICAMENTE INCORRECTA
}

\author{
Marcelo Novoa Sepúlveda ${ }^{1}$
}

\begin{abstract}
Resumen: Revisar tres novelas recientes de literatura fantástica chilena nos enfrenta a una problematización poco común en un género marginal. Se trata de poner en evidencia la inadecuada conceptualización ya anticuada para obras ideológicamente contextualizadas en el presente siglo. También, se examina un modelo de análisis dogmático enquistado en presupuestos teoréticos del fantástico europeo.

Palabras-Llave: Lecturas postmodernas, Teorías fantásticas actuales, Discursos heterodoxos.
\end{abstract}

Resumo: Revisar três novelas recentes da literatura fantástica chilena nos coloca diante de uma problematização pouco comumn em um gênero margi- nal. Se trata de pôr em evidência a inadequada conceitualização já antiquada para obras ideologicamente contextualizadas nol presente século. Também se examina um modelo de análise dogmática encrustado em pressupostos teóricos do fantástico europeu.

Palavras-Chave: Leituras pós-modernas, Teorias fantásticas atuaies, Discursos heterodoxos.

\section{1.}

Aquí nos proponemos alegar contra algunas de las definiciones más ortodoxas de literatura fantástica o de lo fantástico (es decir, las de Caillois, Vax y Todorov), sumadas a las voces latinas que les releen (Barrenechea,

\footnotetext{
${ }^{1}$ Poeta, guionista, editor y crítico literario. Académico de la Universidad Diego Portales (UDP), Santiago de Chile, y de la Pontificia Universidad Católica de Valparaíso (PUCV), Valparaíso, Chile; Doctor en Literatura; Fundó la Editorial Trombo Azul de Valparaíso pu- blicando $L P$ (1987) y Minorías (1988). Luego: Arte Cortante (1996-2003). También: Álbum de Flora y Fauna (2002), ensayos/críticas sobre libros/autores porteños del s. XX. Y la an- tología más completa sobre/desde literatura porteña: Letras en Valparaíso (2010, Edi- ción Consejo de Rectores V Región). En su editorial Puerto de Escape, ha publicado: Años Luz. Mapa Estelar de la Ciencia Ficción en Chile (2006), además de 21 novelas, cuentos y ensayos de los nuevos cultores del género fantástico de nuestro país. Dirige la página de rescate y debate sobre el género en Latinoamérica: www.puerto-de-escape.cl que le convirtieron en referente obligado en la escena fantástica en habla hispana. Endereço eletrônico: editor.marnovoa@gmail.com. Sítio de internet: www.puerto-de-escape.cl.
} 
Campra y de Rivarola); pues encontramos en todas ellas la prevalecencia de un eje axial, redundante a mi parecer, que insiste en concebir la literatura fantástica como un género o una modalidad dual, inclusive tautológicamente, al aludir a esta "dualidad" para explicar la identidad y el funcionamiento del texto fantástico mismo. Pues así señalan estos autores, cuando dictaminan que en todos estos relatos regularmente coexisten dos órdenes de acontecimientos, que separían el mundo "real" del Otro. Y para no parecer un indignado de la teoría, sigo aquí al ensayista cubano, José Miguel Sardiñas, quien nos apoya al exponer:

Hasta ahora el mayor interés de la teoría (de lo fantástico) se ha centrado en la descripción del contacto entre esos dos órdenes y en la del efecto que ese contacto (casi siempre traumático) tiene en el lector real o implícito, sin demasiadas precisiones a este último respecto ${ }^{2}$.

A fin de cuentos, dichos autores (en disparejos grados y variantes, por cierto) nos repiten: el relato fantástico siempre buscará potenciar su capacidad de impresión emocional ante el lector, ya sea por la oscilación (o vacilación, según la traducción al uso) entre las posibilidades humanas y sobrenaturales de explicación de los sucesos narrados; o bien, al contraponer las leyes del mundo familiar y/o conocido por nosotros al enfrentar leyes desconocidas de sucesos en apariencia sobrenaturales, extraños o maravillosos.

Todo lo cual sólo expresa un relativismo dogmático, pues señalaría que, a diferencia de otros géneros industriales en vías de canonización (pienso en el policial o novela negra, que realizó un pacto de no-agresión con el género de aventuras del que proviene ${ }^{3}$, dando a luz un bastardo llamado thriller); pues estos teóricos reclaman a la literatura fantástica que aún no se define a sí misma, pero insisten en filiarla a una taxidermia de géneros ya caídos en desgracia, a saber, gótico para Lovecraft (Todorov), metafísico para Borges o filosófico para Calvino (Vax), pues de otra forma no encajarí- an en sus añejas normativas.

Aquí intentaremos, a su vez, enunciar nuevos niveles textuales para cierta literatura fantástica chilena, facturada en el siglo XXI, que no obedece

2 SARDIÑAS, José Miguel y MORALES, Ana María. Relatos fantásticos hispanoamericanos. La Habana, Fondo Editorial Casa de las Américas, 2003, p. 31.

3 Como bien puede leerse en las filiaciones del género detectivesco de A. Conan Doyle, $H$. R. Haggard y R. H. Bourroughs con el folletín de aventuras decimonónico, en ABRAHAM, Carlos. Estudios sobre Literatura Fantástica. Buenos Aires, Quadrata, 2006, p. 71. 
a las ordenanzas (de la mercadotecnia editorial) para circunscribirse a normas de temporalidad y espacialidad (propias de tanta peripecia futurista deudora del cine sci-fi o animé), ni equilibrarse entre lo animado y lo inerte (tal como ese nuevo naturalismo impuesto por sagas zombis o vampíricas), ni fundamentalmente, discurrir entre los vacíos de la muerte o la expiración (propias del terror paranormal o el gore). Pero sí, estas nuevas obras bus- can discutir derechamente lo posible y lo imposible, ya no como meras categorías determinadas por nociones de realidad dependientes de esquemas cognitivos específicos, sino como enquistamientos textuales históricamente anclados a sistemas ontológicos dominantes. $Y$ aquí nos referimos al orden del capitalismo y su manifestación más salvaje, el neoliberalismo.

2.

Sin embargo, existiría en la literatura chilena, posterior al s. XX (para diferenciarlos de autores de las décadas de 1980 al 2000, aún en producción) un grupo significativo de textos de esta novedosa modalidad narrativa (fantástica) ${ }^{4}$ en los que la Otredad no designa solamenteun estatuto ontológico, sino que, precisamente por lo que indicaremos, aparece como un rasgo ideológico diferenciador altamente provocativo en su desviación de la norma en la escasa y casi nunca bien estudiada narrativa fantástica chilena actual.

La politización, enfática y polemizante es una recordada característica de todas las manifestaciones de la cultura chilena anti-dictadura, y en general, de todos los discursos sociales (religioso, histórico, filosófico, económico, sociológico) que hoy podríamos llamar "pro-concertacionistas" ubicados temporalmente (desde 1986 en adelante). Recordamos aquí que la política afloraba de la manera más obvia, y a veces también, más extemporánea, tanto en un poema como una intervención plástica, una pieza musical o un documental. Y cuando algún artista intentaba mantenerse al margen de tan obsesa "resistencia", inmediatamente caía en el fangoso terreno del apoliticismo, que por omisión, significaba otra postura política,

\footnotetext{
${ }^{4}$ También señalo que deberán ser incluidos en este apartado, como precursores, otras obras chilenas inclasificables, tales como: El color de la amatista de Sergio Meier (1988), El mercenario ad honorem de Gregory Cohen (1989) y El hipódromo de Alicante y La casa de Abadatti de Héctor Pinochet (1986 y 1989).

${ }^{5}$ SUBERCASEAUX, Bernardo. Historia de las ideas y de la cultura en Chile: Tomo II. Santia- go de Chile, Universitaria, 1997, p. 87
} 
tan desgastada como la antes señalada. Mas hoy las coordenadas han mutado, edificando descoloridos escenarios ante públicos altamente refractarios, como lúcidamente expone el filósofo alemán, Sloterdijk:

La masa postmoderna es una masa carente de todo potencial, una suma de micro-anarquismos y soledades que apenas recuerda la época en la que ella - excitada y conducida hacia sí misma a través de sus portavoces y secretarios generales- debía y quería hacer historia en virtud de su condición de colectivo preñado de expresividad ${ }^{6}$.

En un principio, en muchos cuentos y novelas fantásticas latinoamericanas, hoy canónicas (pensemos en Borges, Bioy Casares, Cortázar, Fuentes, Donoso y García Márquez, entre otros) predominaban los temas del 'yodual' y se escatimaban, en cambio, los del 'tú-posible'. Es decir, predominaban los temas relacionados con la percepción del mundo por parte del sujeto de la historia, y escasean los que abarcaran otros fenómenos, como la vida interior o no-física de personajes, que al no lograr encajar sus circunstancias vitales en entornos sociales tan rotundamente fracturados, como son los caminos de retorno a la Democracia, se vieron reconvertidos en vías de evacuación al libre mercado, en nuestros países postdictatoria- les. Nuevamente Sardiñas viene en nuestra ayuda, al señalar que

En todos estos casos, lo Otro - como categoría general opuesta a lo Real, no al yo- es una forma opaca del orden, es un orden que se encuentra fuera del alcance de la comprensión humana normal [...] Indica, en fin, el estatuto ontológico de unas cosas, por contraposición con otras. $Y$ en general, esa forma de la otredad parece describir adecuadamente la mayor parte de los textos fantásticos tanto europeos como estadounidenses o latinoamerica$\operatorname{nos}^{7}$.

Queremos barajar, entonces, tres obras casi desapercibidas por la crítica literaria, tanto regional como nacional como punta de lanza de esta revisión del género fantástico en Chile. Nos referimos a: En todos los burdeles del mundo de Miguel Vargas (2007); El tarot de la locura de Christian Leiva-Ceballos (2010) y Eucalipto Ciudad Paranoia de Baldo Riedemann (2012), todas ellas publicadas por Puerto de Escape, un proyecto editorial

SLOTERDIJK, Peter. El desprecio de las masas. Ensayos sobre las luchas culturales de la sociedad moderna Valencia, Pre-textos, 2001, p. 17-18.

7 SARDIÑAS, J. M. Op cit, p. 47

110 Número temático: Vertentes do insólito nas literaturas das Américas. A Cor das Letras UEFS, n. 15, 2014 
regional $^{8}$ dedicado a difundir obras literarias de fantasía, ciencia ficción y terror chilenas actuales.

En las historias que pronto examinaremos, por el contrario, predominará una relación pasiva no-neutral entre el personaje y el universo, que se resolverá como relación de autodefensa, ya no de ocultación, sino algo más parecido al camuflaje o la simulación, en una actitud político-ideológica impropia de estos tiempos líquidos ${ }^{9}$ que corren, como bien puntea Vásquez Rocca

La modernidad líquida - como categoría sociológica - es una figura del cambio y de la transitoriedad, de la desregulación y liberalización de los mercados. La metáfora de la liquidez - propuesta por Bauman - intenta también dar cuenta de la precariedad de los vínculos humanos en una sociedad individualista y privatizada, marcada por el carácter transitorio y volátil de sus relaciones.

Así, los personajes excepcion a les que comparecerán en dichas historias se nos muestran en total fuga frente al mundo que los rebasa y que ellos se niegan a asimilar. Pero, he aquí su novedad, viven esta decrepitud acelerada de su inocua perplejidad inspirando simpatías en el lector-que- haperdido-la-inocencia, a contracorriente del temor o la maravilla características de muchas historias fantásticas anteriores.

3.

a)

En su archiconocido texto "Lo ominoso" (1919), Freud lo define como aquello que "no es efectivamente algo nuevo o ajeno, sino algo familiar de antiguo a la vida anímica, sólo enajenado de ella por el proceso de la represión". Y Miguel Vargas, con su novela En todos los burdeles del mundo, irónica hasta el sarcasmo, hipercultas in pedanterías, pero infinitamente desolada y angustiosa, nos expone aquello que debería estar oculto, produciéndose así en el sujeto-lector y ya no en el protagonista, un efecto angustioso y perturbador. Pues trastoca lo que Freud denominó: "lo ominoso de la ficción" al colocar como protagonista a un inexperto novelista que

\footnotetext{
${ }^{8}$ Tal como se anuncia en su sitio web: Puerto de Escape, la respuesta chilena a la Literatura Fantástica y Ciencia Ficción en lengua española. Ver: http://www.puerto-de-escape.cl/.

${ }^{9}$ VASQUEZ ROCCA, Adolfo. Zygmunt Bauman: Modernidad Líquida y Fragilidad Humana. Nóma- das, Revista Crítica de Ciencias Sociales y Jurídicas. Universidad Complutense de Madrid, n. 19 (I), p. 309316, 2008. Disponível em: http://www.ucm.es/info/nomadas/19/avrocca2.pdf.
} 
muere antes de completar su obra, y deberá pactar con el diablo, robando la novela de otro aún más inoficioso narrador que nunca se entera que está siendo suplantado. Todo esto en base a un ingenioso y retorcido juego de citas-espejo que terminarán por relacionar lo que el sujeto/lector se representa al leer, con lo que el escritor/objeto supone que es actualmente la literatura: un vaciadero fantasmático, sin gloria ni novedad.

Se trataba de un texto pequeño, un octavo de folio aproximadamente, completamente cubierto de polvo. [...] El grimorio, que tanto necesitaba Toby para su invocación, era, nada más y nada menos, que una edición pocket del "Golem" ${ }^{100 "}$ de Alfred Bester.

— ¡Pero si éste es un libro de ciencia ficción! - exclamé.

- Nadie te dijo que no lo fuera - contestó Toby.

- ¡Pero cómo pretendes invocar al Diablo con una novela de ciencia ficción de 1980 !

-Ah, el tiempo, qué importancia tiene el tiempo ${ }^{10}$.

Entonces, el texto ficcional contenido En todos los burdeles del mundo corroe el efecto ominoso canónico, al situar(se) autor/narrador, en apariencia, en el mundo material donde vive el lector (fantasma omnipresen- te), introduciendo en su lectura de género (narración de ultratumba) los acontecimientos reales que allí ocurren, presentados mañosamente como ficcionales, a la vez que autentificados como biográficos. Trasmitiendo así, una tensa descarga existencial en nosotros, difícil de superar luego de su lectura atenta.

Odio la violencia, huyo de ella [...] de la pupila ensangrentada, de la riña, de la guerra, cualquiera que sea, del conflicto, de tan sólo levantar la voz, de todo lo que desconozco pero intuyo, huelo, respiro, presiento, de aquello que me enferma (el horror, el horror) huyo en un círculo cerrado, sin discontinuidades, sin saltos, huyo directo hacia donde no quiero ir ${ }^{11}$.

\section{b)}

La literatura fantástica, en su vertiente esperpéntica (Bajtín dixit), tienta nuestra risa en los enlazados relatos tiernos y feroces, poéticos y esotéricos de El tarot de la locura de Christian Leiva-Ceballos. Pues la ironía, la sorna y la carcajada, actúan como constante catalizador de la concepción de lo Real, revelándonos las tensiones y armonías entre autor-narrador y

10 En todos los burdeles... p. 45

11 Op. cit., p. 115.

112 Número temático: Vertentes do insólito nas literaturas das Américas. A Cor das Letras UEFS, n. 15, 2014 
mundo extraliterario, al tiempo que zanjan la discusión entre lo correcto e incorrecto en materia ficcional. Así, desde la denominación degradada de Payaso Dos para el protagonista, que trata de escapar de su destino manifiesto (familiar, social y político) que lo llevará al fracaso y la locura. Hasta el uso consciente y liberador de las sucesivas tiradas adivinatorias del Tarot, con toda la ironía contenida en su meta-discurso (pues nadie parece perca- tarse de los sucesos no-realistas que se suceden a su alrededor); originando una puesta en escena carnavalesca "a la chilena" que no produce el distanciamiento esperable de los textos paródicos tradicionales. Sino, contrariamente, re-inventa aquí una actitud político-existencial, deudora de las simetrías y asimetrías entre autor histórico y mundo ficcionalizado ${ }^{12}$, al narrarlas desde lo irreal-aparente que brota de lo real-invisible, trocando su rol alegórico en denuncia política trascendente.

La pantalla muestra al payaso, contemplando una alta palmera, única en medio de un paisaje verde donde recién ha cesado la lluvia. [...] La película termina, las luces se encienden, es de día, los rayos de sol ciegan los ojos de Payaso 2, que está sentado en medio de una plaza desierta. No hay rastros del cine, sólo ecos de una canción desconocida ${ }^{13}$.

Para finalmente, con tanta ironía a cuestas, revelarnos lo fantástico, aquello Otro, como un mensaje roto, que al no contar con una sintaxis tolerante del receptor burgués acostumbrado a descifrar o completar los vacíos inherentes al discurso simbólico esperable, quede atrapado en el enigmático final irónico, sin solución posible. Pues lector y autor deberán seguir padeciendo la omisión de lo Real, más allá de cualquier proceso dialéctico trascendental, que nos hubiera permitido deducir el significado oculto y pretencioso, que aquí brilla por su ausencia delatora, estallándonos en la cara, como risa fácil que nos exculpara de nuestra necesaria complicidad.

Se le viene a la memoria el desfile de gentes con muletas que hoy ha visto pasar y algo en las muletas hacen de la coincidencia una causa, su reiteración en un universo de mesas de café. Algo en las muletas lo lleva desde sí mismo, hacia ese batallón de cojos, inválidos, baldados y menoscabados. Puede, aunque no quiere, reconocer las heridas de cada uno de ellos ${ }^{14}$.

\footnotetext{
${ }^{12}$ Y que sólo en apariencia seguiríanla estrategia textual del Jodorowsky más esotérico (y anti-ideológico, por ende).

13 El Tarot... p. 73.

14 Op. Cit, p. 125.
} 
c)

Por último, Rosemary Jackson, quien criticó a Todorov su escaso interés en el psicoanálisis, hace explícita la función de la literatura fantástica, cuando ésta subvierte lo real establecido señalando lo que estaba oculto en "el intento de hacer visible lo que es culturalmente invisible". Desde un original punto de vista social, Jackson otorgará a la literatura fantástica la capacidad de transgredir las normas sociales, mostrando aquellos temas silenciados: "al poner en descubierto cosas que deberían permanecer a oscuras".

Y ésta es justamente la tarea de demolición autoimpuesta por la novela-río: Eucalipto Ciudad Paranoia al destrenzar una caótica, delirante y poéticamente evocadora serie de diatribas esotéricas, diálogos alucinógenos y eventos paranormales, que buscan escribir la fábula del desconsuelo de cierta generación adolescente actual chilena (post-dictadura), que duda de todas sus certezas, maquinando a favor de una total disolución de lo Real en múltiples, pero nunca infinitas, variantes de la conspiranoia (la idea de una conspiración global sin fin), que funciona tanto como modalidad portátil del consumo, como nuevos efluvios de ciertas espiritualidades sel- ladas al vacío.

El sol cálido y naranjo del preludio al atardecer ilumina nuestra realidad tal como a tantas otras civilizaciones que antes lo adoraron como la divinidad que es; nada impide que en otro plano su núcleo se trate de la conciencia de un ser ascendido que fuma opio en sincronía con otros soles drogadictos que también meditan en su propia locura de mundo inventado, cada uno con su harén de planetas femeninos orbitándole alrededor ${ }^{15}$.

Así, esta novela-en-suspensión se solaza en crear planos narrativos superpuestos, mediante la resignificación de música verbal e imágenes hipnagógicas, con tantos planos narrativos como personajes funambulescos deambulan por ellos; quienes relatarán, a la vez, una misma historia que se descuenta a sí misma, en cada sustitución de personalidad, en cada viraje dramático o en cada celaje de turbia lucidez de los diálogos y monólogos, rozando la genialidad. Aquí no se trata de contar historias de manera desacostumbrada, sino que la palabra escrita presenta un esfuerzo retórico, cuya finalidad es no contar más historias, abolirlas en una hecatombe final, que por fin, nos conduzca a parte alguna. Sea ésta la salida, el exterminio o la vacuidad. Qué más da, ésa pareciera ser la amarga enseñanza del legado

15 Eucalipto Ciudad Paranoia, p. 133.

114 Número temático: Vertentes do insólito nas literaturas das Américas. A Cor das Letras UEFS, n. 15, 2014 
fantástico que recoge este ambicioso relato coral. Todo es visible, pues no queda sitio donde podamos ocultar nuestra falta de transparencia.

\begin{abstract}
Visualizo la habitación desde la eternidad, me pongo turnio: la pieza se plaga de células microscópicas que texturizan todo como gusanillos luminosos multicolores en una reacción a la luz [...]; de pendejo le preguntaba a mi abuela qué eran esas lucecillas que componían todo y no me entendía, jamás lo hizo, decía que era la ampolleta; cuánta lucidez iluminada perdida pasados los siete años cuando los niños naturales frescos de divinidad enfrentan el juego adulto del sigiloso infinito acabado y mueren todos los amigos imaginarios que son lo único real en este mundo... ${ }^{16}$
\end{abstract}

4.

Sabemos que la otredad fantástica es un concepto amplísimo, como ha quedado manifiestoen el sucinto recorrido teórico del inicio. No obstante, el componente político divergente no parece haberse detectado hasta ahora, por lo menos no como rasgo constitutivo, ni hasta donde sé, su presencia haya sido señalada precisamente como "común denominador", o uno de ellos, del nuevo relato fantástico. Sino que se sigue insistiendo en la dimensión simbólica del fantástico latinoamericano clásico por el simple expediente de subvertir un lenguaje normado, como majaderamente señala Barrenechea, utilizando a Cortázar (quizás el autor más político del boom) como tabla rasa de salvación de su teoría

Esta posición o la de un Julio Cortázar que cifra la función revolucionaria del artista en revolucionar el ámbito de las formas [...], abre también al género otras posibilidades bajo el signo de lo social, siempre que lo fantástico sea una puesta en cuestión de un orden viejo que debe cambiar urgentemente ${ }^{17}$.

En definitiva, en todas estas narraciones mencionadas, quisiéramos señalar que los tiempos regresivos allí expuestos, los espacios enquistados descritos y sus personajes pasivos-activos protagónicos, constituyen una cabal representación de Otredad que, al contrario de las teorías más conocidas y aun en boga de lo fantástico, estarían escenificando una novedosa complejización de lo sobrenatural, lo paranormal y lo anómalo, en cada caso estudiado, dirigiendo nuestra atención hacia una peculiaridad simbóli-ca con fuerte contenido político ideológico, no programático, dado su ele-

\footnotetext{
16 Op. cit, p. 194.

${ }^{17}$ BARRENECHEA, Ana María. La Teoría de lo fantástico en Latinoamérica. Buenos Aires, Sudamericana, 1979, p. 67.
} 
mento paródico, ominoso y subversivo, presente en todos ellos. Tal como sucedió a fines del siglo XIX con los cuentos de E. A. Poe, que llevan el fantástico y el terror europeos hasta una nueva dimensión en América, como plantea el estudioso español, David Roas:

Por el contrario, lo fantástico (en Poe) nos sitúa inicialmente dentro de los límites del mundo que conocemos, del mundo que (digámoslo así) controlamos, para inmediatamente quebrantarlo con un fenómeno que altera la manera natural y habitual en que funciona ese espacio cotidiano. $Y$ eso convierte a dicho fenómeno en imposible, $y$, como tal, inexplicable ${ }^{18}$.

Desde luego, más adelante será posible caracterizar en profundidad, o bien, enriquecer con nuevos elementos de análisis esta breve indagación temática, siempre dentro del debido proceso de ampliación del panorama de la literatura fantástica chilena actual que nos hemos impuesto. Sin embargo, en esta aproximación crítica mi propósito ha sido sólo señalar su aparición nodal y ofrecer una descripción de carácter primario, ambas señales, que hasta donde sé, no se ha habían ensayado.

\section{REFERENCIAS}

ABRAHAM, Carlos. Estudios sobre Literatura Fantástica. Buenos Aires, Quadrata, 2006.

BARRENECHEA, Ana María. Ensayo de una tipología de la literatura fantástica. Caracas, Monte Ávila, 1978.

BARRENECHEA, Ana María. La Teoría de lo fantástico en Latinoamérica. Buenos Aires, Sudamericana, 1979.

BORGES, Jorge Luis, Adolfo BIOY CASARES y Silvina OCAMPO. (Ed.). Antología de la literatura fantástica. Barcelona, Edhasa, 1989.

CAILLOIS, Roger. Del cuento de hadas a la ciencia-ficción. La imagen fantástica. Buenos Aires, Sudamericana, 1970.

CAMPRA, Rosalba. Il fantástico: una isotopía della trasgressione. Roma, Strumenti Critici, 1981.

JACKSON, Rosemary. Fantasy: literatura y subversión. Buenos Aires, Catálogos, 1986.

FREUD, Sigmund. Lo ominoso. In: Obras Completas (vol. XII). Buenos Aires, Amorrortu, 1991.

18 ROAS, David. Poe y lo grotesco moderno [artículo en línea]. 452ºF. Revista Electrónica de Teoría de la Literatura y Literatura Comparada, n. 1, 2009, p. 17.

116 Número temático: Vertentes do insólito nas literaturas das Américas. A Cor das Letras UEFS, n. 15, 2014 
LEIVA-CEBAlLOS, Christian. El Tarot de la Locura. Chile, Puerto de Escape, 2010.

RIEDEMAN, Baldo. Eucalipto Ciudad Paranoia. Chile, Puerto de Escape, 2012.

ROAS, David. (Ed.). Teorías de lo fantástico, Madrid, Arco, 2001.

ROAS, David. Poe y lo grotesco moderno [artículo en línea]. 452% F Revista Electrónica de Teoría de la Literatura y Literatura Comparada, n. 1, 2009

SARDIÑAS, José Miguel. El orden alterno en algunas teorías de lo fantástico y el cuento cubano de la revolución. Revista Casa de las Américas, Cuba, n. 141, p. 12-28, 2001.

SARDIÑAS, José Miguel y MORALES, Ana María. Relatos fantásticos hispanoamericanos. La Habana, Fondo Editorial Casa de las Américas, 2003.

SLOTERDIJK, Peter. El desprecio de las masas. Ensayos sobre las luchas culturales de la sociedad moderna. Valencia, Pre-textos, 2001.

SUBERCASEAUX, Bernardo. Historia de las ideas y de la cultura en Chile: Tomo II. Santiago de Chile, Editorial Universitaria, 1997.

TODOROV, Tzvetan. Introducción a la literatura fantástica. México D. F., Coyoacán, 2003.

VAX, Louis. L 'art et la littérature fantastiques. París, Presses Universitaires de France, 1974.

VARGAS, Miguel. En todos los burdeles del mundo. Puerto de Escape, Chile, 2007.

VASQUEZ ROCCA, Adolfo. Zygmunt Bauman: Modernidad Líquida y Fragilidad Humana. Nómadas, Revista Crítica de Ciencias Sociales y Jurídicas. Universidad Complutense de Madrid, n. 19 (I), p. 309-316, 2008. Disponível em: http://www.ucm.es/info/nomadas/19/avrocca2.pdf. 
